\title{
Performance of a Dual, 1200 V, 400 A, Silicon-Carbide Power MOSFET Module
}

\author{
Damian Urciuoli \\ damian.urciuoli@us.army.mil
}

\author{
Ronald Green \\ ronald.greenjr@us.army.mil
}

\author{
Aivars Lelis \\ aivars.j.lelis@us.army.mil
}

\author{
Dimeji Ibitayo \\ dimeji.ibitayo@us.army.mil
}

U.S. Army Research Laboratory, 2800 Powder Mill Road, Adelphi, MD, 20783 USA

\begin{abstract}
A dual $1200 \mathrm{~V}, 400$ A power module was built in a half-bridge configuration using 16 silicon-carbide $(\mathrm{SiC}) 0.56 \mathrm{~cm}^{2}$ DMOSFET die and $12 \mathrm{SiC} 0.48 \mathrm{~cm}^{2} \mathrm{JBS}$ diode die. The module included high temperature custom packaging and an integrated liquid cooled heat sink while conforming to the footprint and pinout of a commercial dual IGBT package. Die encapsulant was not used, to allow data collection by infrared thermal imaging. The module was DC tested at currents up to $400 \mathrm{~A}$ and coolant temperatures up to $100{ }^{\circ} \mathrm{C}$. Switching was evaluated in a boost converter at load power levels up to $25 \mathrm{~kW}$ and at frequencies up to $30 \mathrm{kHz}$ with coolant temperatures up to $80{ }^{\circ} \mathrm{C}$. Acceptable current sharing between MOSFET die was observed over the switching frequency and coolant temperature ranges. Package thermal resistances and MOSFET and diode power losses were characterized. Results were compared to those simulated for a 400 A IGBT module.
\end{abstract}

\section{Index Terms - Power MOSFETs}

\section{INTRODUCTION}

Silicon-carbide $(\mathrm{SiC})$ power electronic devices offer higher temperature operation, higher breakdown voltage limits, and lower losses than their Si counterparts [1]. These features provide critical performance benefits for power electronic systems, especially those of the automotive sector where higher temperature and more compact operating environments are common. SiC based power converters have been proposed to replace Si IGBT based units and support hybrid electric drive systems with thermal management provided by engine coolant at temperatures up to $100{ }^{\circ} \mathrm{C}$. Improvements in $\mathrm{SiC}$ device technology in recent years have enabled large area junction barrier Schottky (JBS) diode and DMOSFET (doubly-implanted MOSFET) development [2],[3]. Recently fabricated advanced research and development engineering samples of these two types of devices having total chip areas of $0.48 \mathrm{~cm}^{2}$ and $0.56 \mathrm{~cm}^{2}$, respectively, were used to develop a $1200 \mathrm{~V}, 400 \mathrm{~A}$ dual all $\mathrm{SiC}$ power module in a half-bridge configuration.

In previous work, $0.56 \mathrm{~cm}^{2} \mathrm{SiC}$ MOSFETs were copackaged to form $100 \mathrm{~A}$ single switch modules. The modules were evaluated in a switching converter at rms currents up to 90 A using $60{ }^{\circ} \mathrm{C}$ to $90{ }^{\circ} \mathrm{C}$ coolant. Projected die temperatures for the tests exceeded $180{ }^{\circ} \mathrm{C}$ as discussed in [4]. Fig. 1 shows typical MOSFET drain current versus drain-to-source voltage curves, and Fig. 2 shows typical MOSFET ON-state resistance versus temperature. Although these relationships are typical, they can vary slightly between die. The MOSFETs were conservatively rated at $50 \mathrm{~A}$ each $\left(223 \mathrm{~W} / \mathrm{cm}^{2}\right)$ based on modeling and measured thermal resistances.

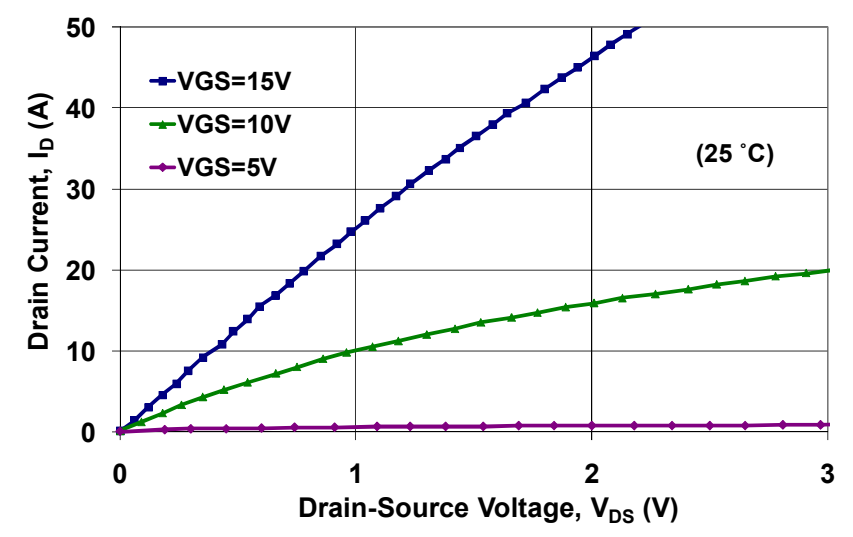

Fig 1. Typical $\mathrm{SiC} 0.56 \mathrm{~cm}^{2}$ MOSFET $\mathrm{I}_{\mathrm{D}}$ vs. $\mathrm{V}_{\mathrm{DS}}$

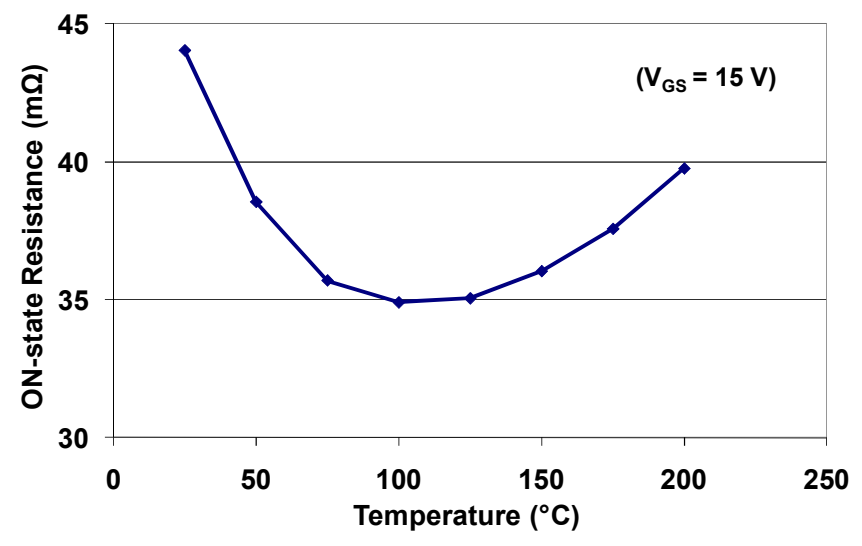

Fig 2. Typical SiC $0.56 \mathrm{~cm}^{2}$ MOSFET $\mathrm{R}_{\mathrm{DS}-\mathrm{ON}}$ vs. temperature

Based on the favorable performance of the 100 A single switch modules, it was necessary to determine the feasibility of placing a greater number of die in parallel per switch. Measurement of current sharing effects for DC at die temperatures below and above that corresponding to minimums in ON-state resistance was needed. Information about the sharing of transient currents in a power switching application over a range of frequencies, and the effects of parasitic inductances introduced in packaging was also important. Finally, characterization of package thermal 
resistance and switch and diode power losses over the frequency range were also desired.

\section{Module Design AND FABRICATION}

Building a high-current dual $1200 \mathrm{~V}$ prototype module in a half-bridge configuration was proposed for its applicability to most inverters and DC-DC converters. A SiC MOSFET module was built to be compatible with a $300 \mathrm{~A}$ to $400 \mathrm{~A}$ commercially available dual IGBT module package with nominal footprint dimensions of $106 \mathrm{~mm}$ by $62 \mathrm{~mm}$, enabling it to be evaluated in many existing systems. The module has eight parallel $0.56 \mathrm{~cm}^{2} \mathrm{SiC}$ MOSFETs, and six $0.48 \mathrm{~cm}^{2}$ antiparallel SiC JBS diodes per switch. For improved thermal performance, the design incorporates a low profile integrated liquid cooled heat sink while maintaining the standard overall module height of $31 \mathrm{~mm}$ [5].

Integration of the heat sink into the module provides advantages over conventional modules having solid base plates. Thermal resistance between the devices and the cooling fluid can be significantly lower using an integrated heat sink. The thermal interface between the devices and the cooling fluid is fixed and not subject to degradation due to time, atmospheric, or environmental conditions. The integrated heat sink is comprised of two machined copper parts that are bonded together; a lid having skived fins, and a cavity having a rigid frame. Two fluid ports are located on the bottom side of the cavity and allow the module to be mounted and sealed to a manifold in the same manner that a conventional module is mounted to its external heat sink. An o-ring seal located in the manifold at each port can be sized for fluid pressure requirements. Computational fluid dynamic simulations show that coolant impingement on the underside of the heat sink lid provides sufficient fluid turbulence for effective heat transfer and flow distribution, eliminating the need for additional physical features [5].

The heat sink was designed for a $50 \%$ aqueous solution of propylene glycol (PGW50/50). Fluid flow and device temperatures for associated power dissipations were simulated using the Cosmos FloWorks ${ }^{\circledR}$ tool of the SolidWorks ${ }^{\circledR}$ design software. Simulations were conducted for flow rates ranging from 1.9 to 11.4 liters per minute (lpm) to map fluid velocities at selected heat sink cross sections. Results over the range showed good flow uniformity over the active cooling areas [5],[6]. Because the heat sink is symmetric along both its length and width, fluid flow in either direction through the ports results in highly symmetric thermal performance. Using this range of flow rates, and for PGW50/50 at up to $100{ }^{\circ} \mathrm{C}$, device temperatures were simulated for operating conditions from which maximum device power dissipations were projected [5].

After machining, the lid and cavity were plated using an electro-less nickel immersion gold (ENIG) process to prevent oxidation and increase solder wetting. The heat sink was bonded together using $97.5 \mathrm{~Pb}-1.5 \mathrm{Sn}-1.0 \mathrm{Ag}$ solder. After passing a 50 psi leak test, the heat sink lid was machined flat to a final thickness of $1 \mathrm{~mm}$ and was re-plated in preparation for substrate bonding [7]. The direct bond copper (DBC) substrate was sectioned into four rectangular quadrants each having four MOSFET die and three diode die. Sectioning the DBC decreased the area of individual substrate-to-heat sink bonds to reduce solder voids at the interface. The substrate copper was plated using the ENIG process and the device-tosubstrate and substrate-to-heat sink interfaces were bonded using $80 \mathrm{Au}-20 \mathrm{Sn}$ and $96.5 \mathrm{Sn}-3.0 \mathrm{Ag}-0.5 \mathrm{Cu}$ solders, respectively in two separate processes. Solder bonds at the heat sink lid-to-cavity, substrate-to-heat sink, and device-tosubstrate interfaces were formed in a vacuum reflow oven. Each solder was selected based on its melting point and its compatibility with the ENIG plating. A scanning acoustic microscope (SAM) was used to identify voids at solder interface layers. Fig. 3 shows a representative scanning acoustic microscope image of the device-to-substrate solder bond with solder voids identified as light or white areas. All solder bonds at the device-to-substrate and substrate-to-heat sink interfaces exhibited very low voiding [7].

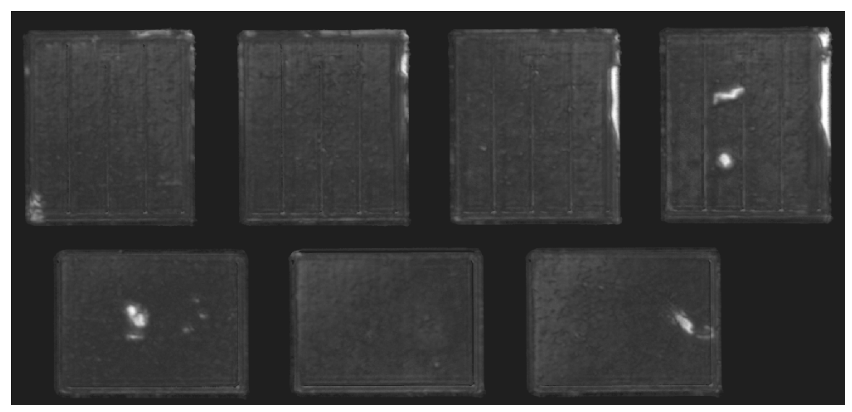

Fig 3. SAM image of device-to-substrate solder bond with voids shown by light or white areas

Devices were wire bonded using $0.3 \mathrm{~mm}$ and $0.13 \mathrm{~mm}$ diameter aluminum wire for all power connections and gate connections, respectively. Terminals were attached to the substrate using $63 \mathrm{Sn}-37 \mathrm{~Pb}$ solder. Finally, a polysulfone plastic case, fabricated using a fused deposition modeling process, holding gate terminals and fastening hardware was affixed [5]. The case was designed to have a removable lid to allow thermal imaging of devices during testing. All materials used in the fabrication of the module are capable of supporting die operating temperatures in excess of $175{ }^{\circ} \mathrm{C}$ and inlet coolant and ambient temperatures exceeding $100{ }^{\circ} \mathrm{C}$. Fig. 4 shows the completed module and an internal view.

Symmetry among gate paths to each MOSFET die was an important consideration in an attempt to match lead inductance and gate transitions. MOSFET die were located along the sides of the module with gate pads facing out for greater accessibility. To ensure gate current sharing between MOSFET die during gate transitions, internal $2.25 \Omega$ SiC gate resistors were used along with a single Kelvin source connection per die. A $0.37 \Omega$ external gate resistor was used during switching tests for transitions of approximately $150 \mathrm{~ns}$ 
depending on module temperature.
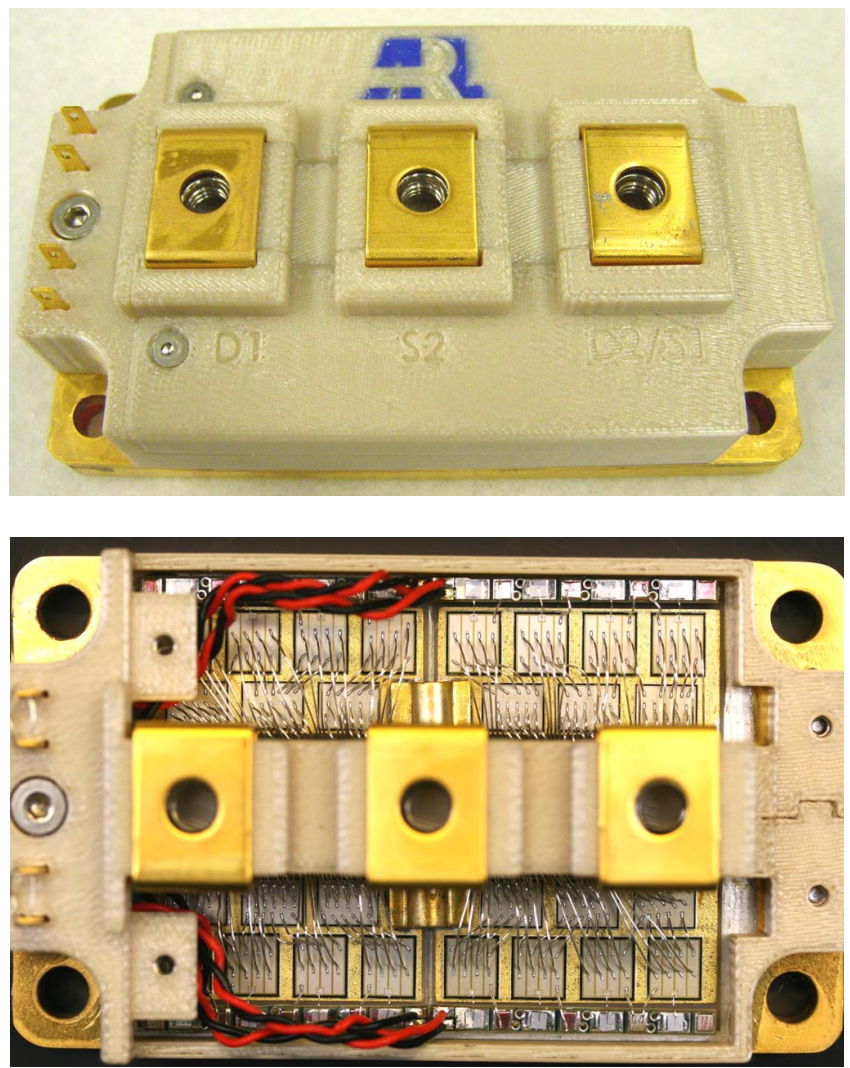

Fig. 4. $1200 \mathrm{~V}, 400 \mathrm{~A}$ all SiC module (top), internal view showing upper switch (Q1) die on top and lower switch (Q2) die on bottom (bottom)

\section{DC CHARACTERIZATION}

Following assembly and device leakage tests, and without encapsulant applied, the interior of the module was sprayed with a thin coating of boron nitride to provide a uniform emissivity to improve the accuracy of thermal measurements using an infrared (IR) camera [8]. IR thermal imaging provides temperatures accurate to $\pm 2{ }^{\circ} \mathrm{C}$ over an entire field of view, and was used to assess device current sharing, monitor device health, and collect device temperatures. Because module encapsulant prevents accurate IR temperature measurements, die encapsulant was not used in this work, thus requiring peak switch voltages and temperatures to be limited during testing. After enough thermal data is collected at lower device voltages and temperatures to extrapolate device conditions in higher power and higher temperature tests, boron nitride could be removed and encapsulant could be applied.

MOSFET current sharing, diode current sharing, and module thermal resistances were characterized through DC testing. Each MOSFET switch was biased with a gate-tosource voltage of $15 \mathrm{~V}$. Drain currents, ranging from 0 A to $400 \mathrm{~A}$ in $50 \mathrm{~A}$ increments, were multiplied by corresponding drain-to-source voltage values to determine switch power dissipation. Diode power dissipation was measured in separate tests with a MOSFET gate-to-source bias of $-10 \mathrm{~V}$. Thermal resistances were calculated using average die temperature rise. PGW50/50 inlet coolant temperatures of 30 ${ }^{\circ} \mathrm{C}, 50{ }^{\circ} \mathrm{C}$, and $80{ }^{\circ} \mathrm{C}$ were used at each of $1.9,3.8$, and 7.6 $1 \mathrm{pm}$ flow rates. Fig. 5 shows thermal images of the upper switch (Q1) and upper diode (D1) die at 400 A using $80{ }^{\circ} \mathrm{C}$ coolant at $3.8 \mathrm{lpm}$. Seven of the eight MOSFET die are visible. Because the long set of wire bonds passing from the MOSFET die over the diode die are hotter than the MOSFETs, MOSFET and diode die temperatures were sampled from die areas unobstructed by wire bonds. Close current sharing between MOSFET die was shown by a $3{ }^{\circ} \mathrm{C}$ range of die temperatures. The estimated standard deviation in MOSFET die current was $2 \mathrm{~A}$, for an average die current of $50 \mathrm{~A}$. The diodes, having an average die current of $67 \mathrm{~A}$, also shared current well with a standard deviation of nearly 3 A, estimated from a $7{ }^{\circ} \mathrm{C}$ range of die temperatures.
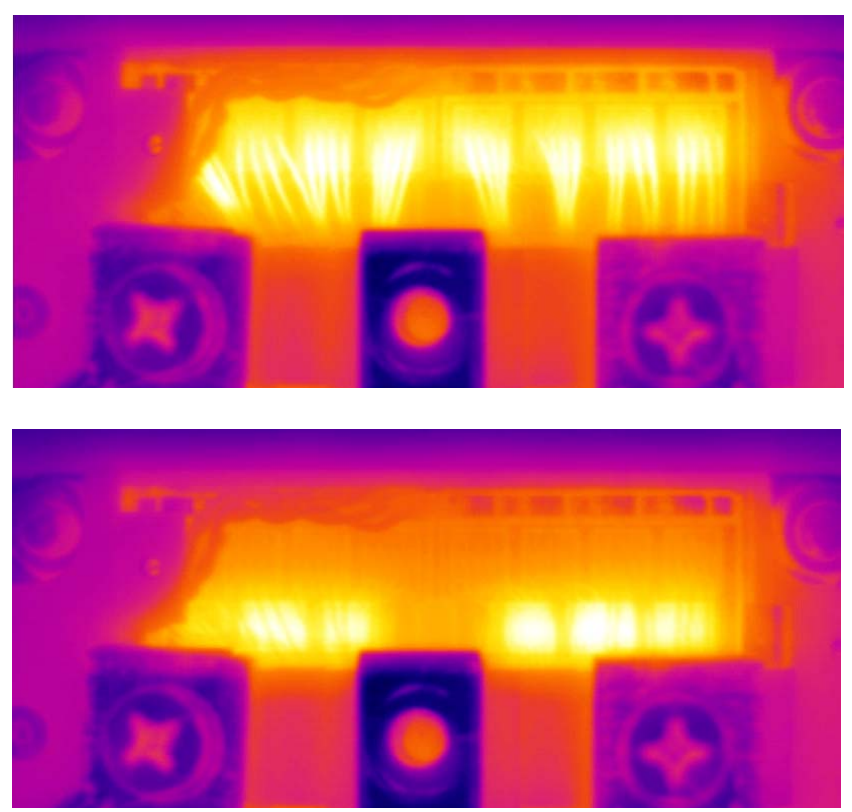

Fig. 5. Q1 and D1 IR images at $400 \mathrm{~A}$ DC using $80{ }^{\circ} \mathrm{C}$ coolant: MOSFETs (top), diodes (bottom)

Table 1 provides data from the upper switch and upper diode $400 \mathrm{~A}$ DC tests for $30{ }^{\circ} \mathrm{C}, 50{ }^{\circ} \mathrm{C}$, and $80{ }^{\circ} \mathrm{C}$ coolant temperatures at a flow rate of $3.8 \mathrm{lpm}$. Power dissipation is the total dissipated power in the conducting devices. $\Delta \mathrm{T}_{\mathrm{AVG}}$ is the average rise in die temperature. $R_{\theta}$ is the normalized thermal resistance of the paralleled devices. Normalized thermal resistance provides a metric for comparing thermal resistances of systems having different thermal fluxes. The data shows the effect of the SiC MOSFET ON-state resistance negative temperature coefficient over this temperature range, and the opposite behavior in the $\mathrm{SiC}$ diodes. The data also shows a decrease in $\mathrm{R}_{\theta}$ at higher die temperatures. This effect is attributed to additional natural 
convection from the non-insulated die surface. Thus, thermal resistance values calculated using $30{ }^{\circ} \mathrm{C}$ coolant tests are more accurate.

TABLE I

400 A DC TEST DATA OF THE UPPER SWITCH AND DiOdE AT A COOLANT FLOW RATE OF 3.8 LPM

\begin{tabular}{|c|c|c|c|c|}
\hline \multirow{4}{*}{ MOSFET } & $\begin{array}{c}\text { Power } \\
\text { Dissipation (W) }\end{array}$ & $\begin{array}{c}\text { Inlet Coolant } \\
\text { Temp. }\left({ }^{\circ} \mathrm{C}\right)\end{array}$ & $\begin{array}{c}\Delta \mathrm{T}_{\mathrm{AVG}} \\
\left({ }^{\circ} \mathrm{C}\right)\end{array}$ & $\begin{array}{c}\mathrm{R}_{\theta}\left({ }^{\circ} \mathrm{C}\right. \\
\left.\mathrm{cm}^{2} / \mathrm{W}\right)\end{array}$ \\
\cline { 2 - 5 } & 734 & 30 & 34 & 0.21 \\
\cline { 2 - 5 } & 711 & 50 & 31 & 0.20 \\
\hline \multirow{3}{*}{ Diode } & 706 & 80 & 29 & 0.18 \\
\cline { 2 - 5 } & 835 & 30 & 46 & 0.16 \\
\cline { 2 - 5 } & 906 & 50 & 49 & 0.16 \\
\hline
\end{tabular}

\section{SWITCHING CONVERTER EVALUATION}

After DC conduction tests, the module was evaluated in a DC-DC converter to provide application data over a broad range of switching conditions. An open-loop boost converter with a fixed resistive load of $4.5 \Omega$ was used to characterize device thermal sharing at load power levels of $10,15,20$, and $25 \mathrm{~kW}$ at switching frequencies from $10 \mathrm{kHz}$ to $30 \mathrm{kHz}$ in 5 $\mathrm{kHz}$ increments. The converter supply voltage was held fixed at $100 \mathrm{~V}$ and load voltages ranged from $209 \mathrm{~V}$ to $325 \mathrm{~V}$ for the four load power levels. Due to parasitic inductances introduced in packaging, peak switch voltages at turn off reached $640 \mathrm{~V}$. Although the devices have voltage blocking ratings of $1200 \mathrm{~V}$, voltages were kept well below that in the absence of encapsulant to allow thermal imaging of the die. PGW50/50 coolant was used at inlet temperatures of 30, 50 and $80{ }^{\circ} \mathrm{C}$ and at a flow rate of $3.8 \mathrm{lpm}$. Fig. 6 shows the test setup with open bussing for thermal imaging, and an IR image of the module during a preliminary $27 \mathrm{~kW}$ test (this load power is greater than that of the switching data presented in this paper) at a switching frequency of $20 \mathrm{kHz}$ with $80{ }^{\circ} \mathrm{C}$ coolant (approximate maximum die temperature is $100{ }^{\circ} \mathrm{C}$ ).

A $0.1 \mu \mathrm{F}$ bypass capacitor on the busbar between the upper drain and lower source connections was moved directly across the module terminals to reduce the peak drain voltage of the lower switch. This capacitor allowed only three MOSFET die to be imaged during testing, which are outlined in Fig. 6. However, the three die are thermally well balanced and provide an accurate representation of the average switch die temperature. Fig. 7 shows MOSFET die average temperature rise $\left(\Delta \mathrm{T}_{\mathrm{AVG}}\right)$ versus module $r m s$ current at a switching frequency $\left(\mathrm{F}_{\mathrm{SW}}\right)$ of $30 \mathrm{kHz}$. Fig. 8 shows MOSFET $\Delta T_{A V G}$ versus $F_{S W}$ for each load power level for 80 ${ }^{\circ} \mathrm{C}$ coolant.

Although Fig. 7 shows the expected result of higher MOSFET die average temperature rise at higher switching frequency, it also shows lower temperature rise at higher die temperatures. This result is supported by the MOSFET ONstate resistance negative temperature coefficient below approximately $100{ }^{\circ} \mathrm{C}$, as shown in Fig. 2 . Fig. 8 shows trends with relatively small increases in die temperature rise over a $10 \mathrm{kHz}$ to $30 \mathrm{kHz}$ range at four converter output power levels.
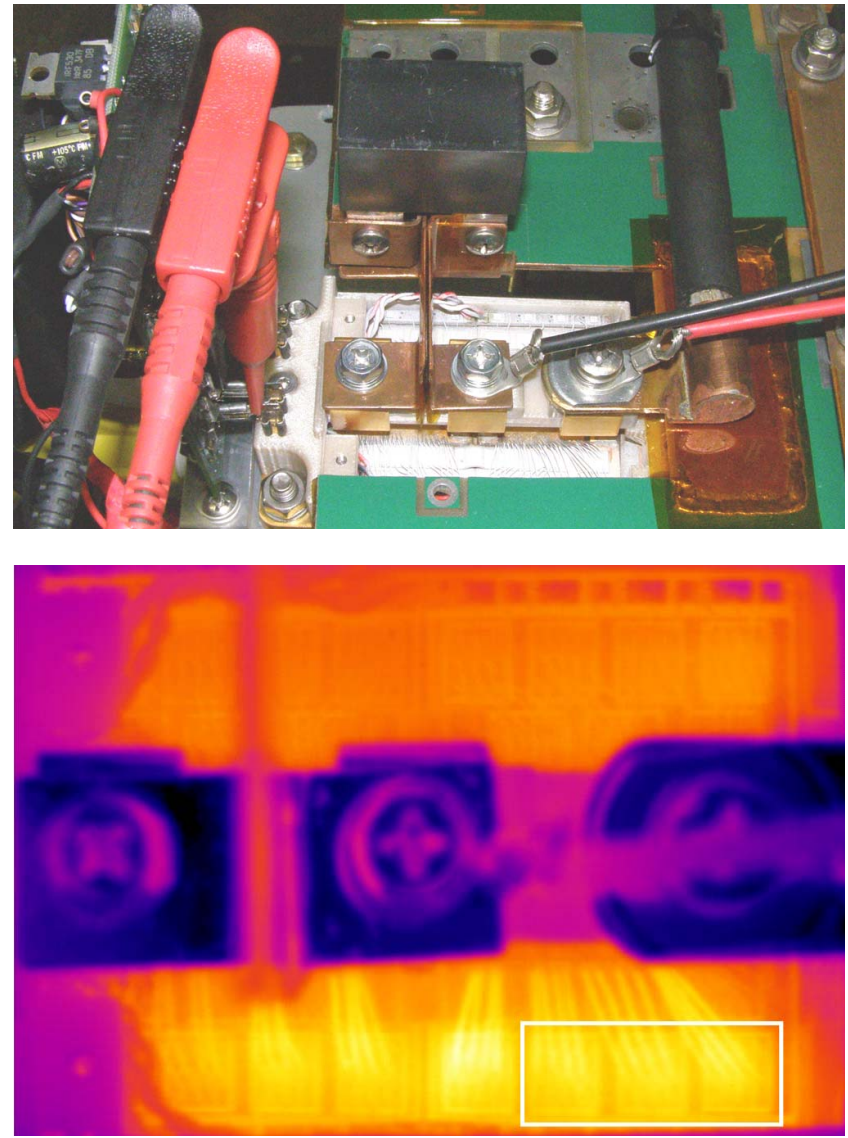

Fig. 6. Test converter (top), MOSFET die IR image $\left(27 \mathrm{~kW}, 20 \mathrm{kHz}, 80{ }^{\circ} \mathrm{C}\right.$ coolant) (bottom)

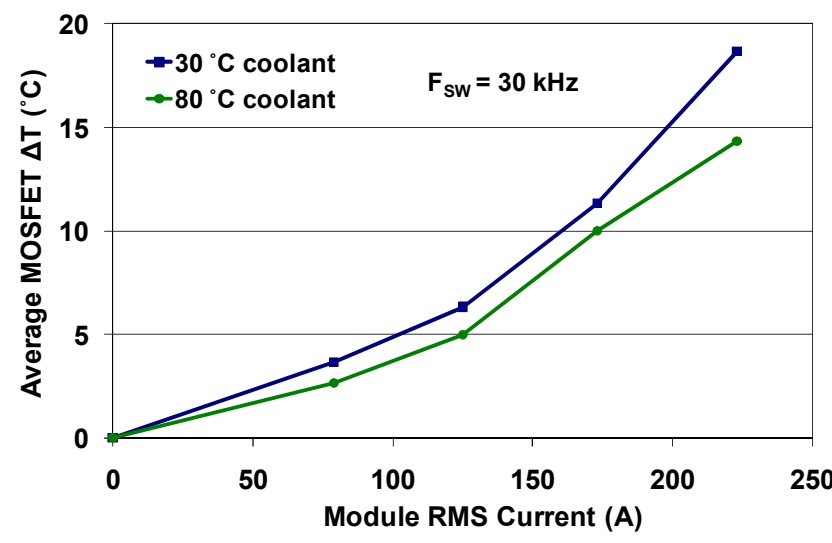

Fig. 7. Average MOSFET temperature rise versus module RMS current

\section{MOSFET VERSUS SiMULATED IGBT PERFORMANCE}

SiC MOSFET module data was used to compare losses to those of an IGBT datasheet driven model, simulated at the same load power levels and switching frequencies. The Eupec FF400R12KT3 dual 400 A Si IGBT module in the Cseries $106 \mathrm{~mm}$ by $62 \mathrm{~mm}$ package was selected for the comparison based on its fast trench/fieldstop IGBT3 devices 
and its EmCon high efficiency diodes. Compared to a low loss IGBT module chipset, the function of the FF400R12KT3 high speed chipset is more closely matched with that of the MOSFET module. The MOSFET average temperature rise values from the $25 \mathrm{~kW}$ load power tests shown in Fig. 8 were used (with a Q2 average normalized thermal resistance of $\left.0.19{ }^{\circ} \mathrm{C} \mathrm{cm} / \mathrm{W}\right)$ to calculate MOSFET power dissipation for each point. IGBT and diode current waveform data was generated by circuit simulations (corresponding to each MOSFET test condition) of an IGBT boost converter model having coefficient based parameters approximating those of the FF400R12KT3 module. The simulation data was imported into Matlab® along with mapped FF400R12KT3 datasheet curves for IGBT turn-on and turn-off energy, collector-emitter voltage, diode reverse recovery energy, and forward voltage. Matlab® was used to calculate module loss contributions from each mapped parameter and total IGBT and diode power dissipation. To ensure accuracy, 2000 data points per period from the circuit simulations and 2500 data points per parameter map were used. Figs. 9 and 10 show the switch and diode power dissipation comparisons, respectively.

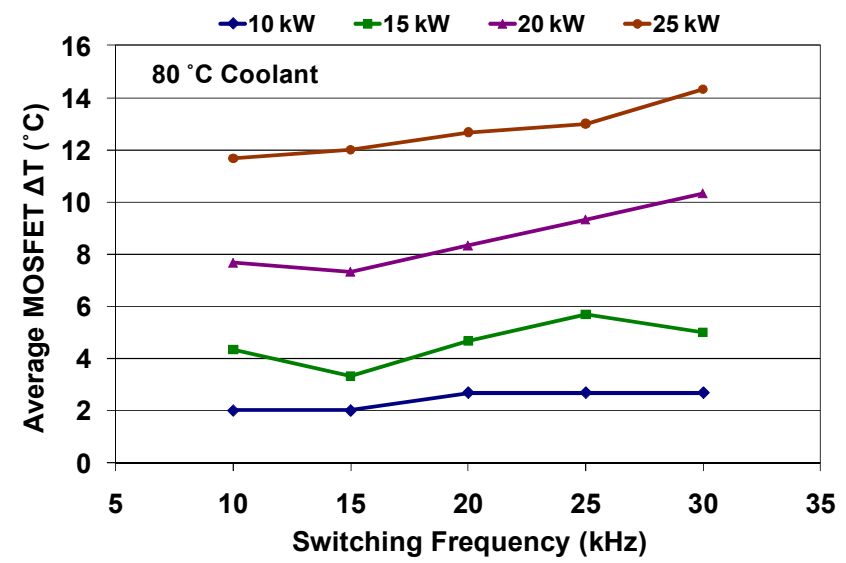

Fig. 8. Average MOSFET temperature rise versus switching frequency for load power

Fig. 9 shows both IGBT and MOSFET power dissipation increasing linearly. With boost converter duty cycle unchanged, rms current is nearly constant over the data range. Inductor current ripple is reduced with increasing switching frequency, resulting in roughly a $10 \%$ decrease in turn-off current (peak inductor current), and a similar increase in turnon current (minimum inductor current). Therefore, conduction losses and total switching energies remain relatively constant, with increased power dissipation simply resulting from increased switching losses at higher switching frequencies. Fig. 9 shows that the SiC MOSFET module has dramatically lower conduction and switching losses than the simulated IGBT module.

It is also important to consider that module loss comparisons were not made for identical operating conditions. MOSFET and JBS diode data correspond to 80
${ }^{\circ} \mathrm{C}$ coolant and median rises in die temperature of $13{ }^{\circ} \mathrm{C}$ and $8.5{ }^{\circ} \mathrm{C}$, respectively. Total IGBT and diode die areas per switch have not been identified. FF400R12KT3 simulations are based on $125{ }^{\circ} \mathrm{C}$ junction temperature data. As an example, FF400R12KT3 IGBT thermal resistance values of $0.062 \mathrm{~K} / \mathrm{W}$ (junction-to-case), and $0.03 \mathrm{~K} / \mathrm{W}$ (case-to-heat sink) give a total thermal resistance of $0.092 \mathrm{~K} / \mathrm{W}$ (junctionto-heat sink). Even assuming a heat sink-to-coolant thermal resistance of zero, the lowest simulated IGBT power dissipation of $861 \mathrm{~W}\left(\mathrm{~F}_{\mathrm{SW}}=10 \mathrm{kHz}, 25 \mathrm{~kW}\right.$ load power) at a die temperature of $125{ }^{\circ} \mathrm{C}$ yields a die temperature rise of 79 ${ }^{\circ} \mathrm{C}$ and a corresponding coolant temperature of $46{ }^{\circ} \mathrm{C}$. Under the same unrealistically favorable assumption, the $20 \mathrm{kHz}, 25$ $\mathrm{kHz}$, and $30 \mathrm{kHz}$ IGBT data points in Fig. 9 would need to have coolant temperatures below $0{ }^{\circ} \mathrm{C}$. The MOSFET and JBS diode losses are dramatically lower than the simulated FF400R12KT3 IGBT module losses. However, a loss per unit of die area comparison cannot be made without directly comparing total module device die areas.

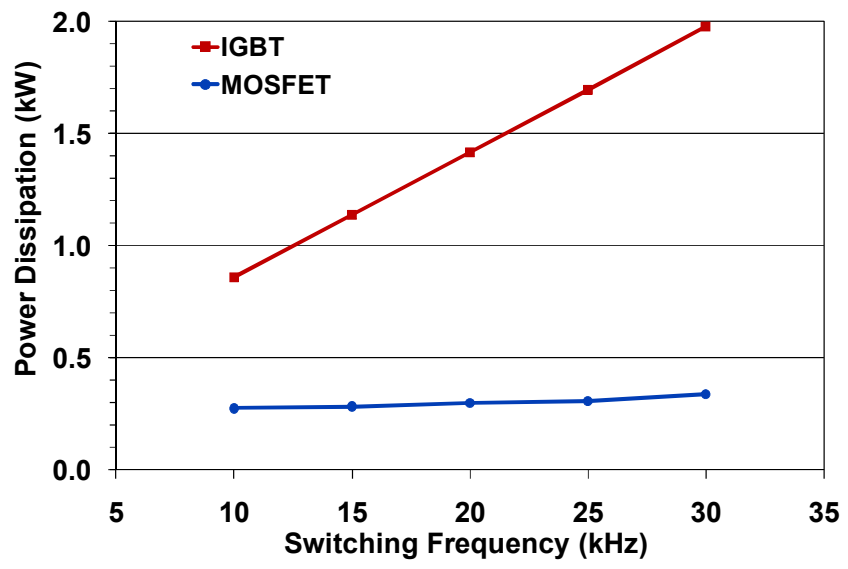

Fig. 9. IGBT (simulated) versus MOSFET (experimental) power dissipation for $25 \mathrm{~kW}$ boost converter load power

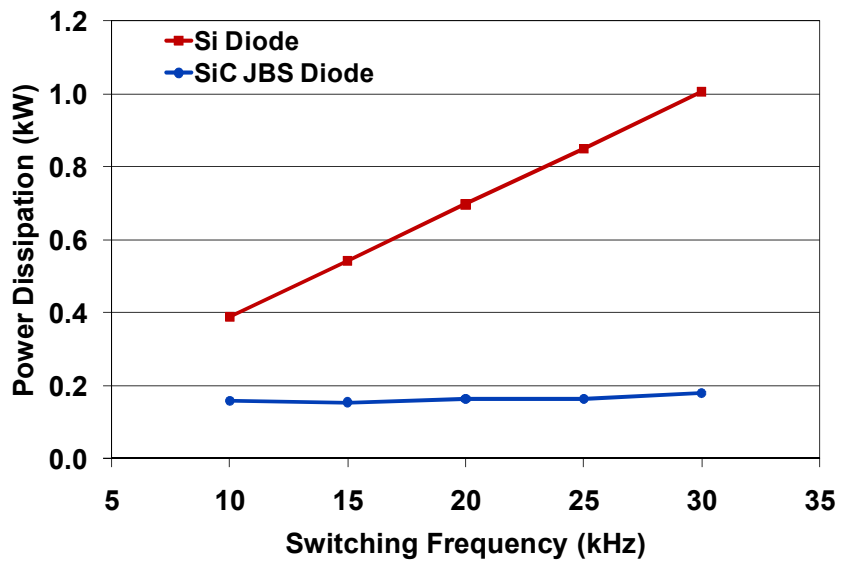

Fig. 10. Si diode (simulated) versus SiC JBS diode (experimental) power dissipation for $25 \mathrm{~kW}$ boost converter load power

In some applications, the $\mathrm{SiC}$ MOSFET module can benefit from further reductions in power dissipation through 
MOSFET synchronous rectification. Recent switching evaluations of the $0.56 \mathrm{~cm}^{2} \mathrm{SiC}$ MOSFETs with SiC JBS diodes have shown total rectification power loss reductions up to $50 \%$ using synchronous rectification in a buck converter, compared to JBS diode freewheeling alone [9]. Data supporting the results showed that MOSFET ON-state resistance during reverse conduction was nearly identical to that for forward conduction. Module current can be limited by maximum diode junction temperature in buck, boost, or other converter or inverter implementations having unsymmetrical current between the symmetrical switches of a half-bridge power module. In these applications, synchronous rectification loss reductions can allow higher current or higher frequencies to be reached. This assessment is supported by the DC data shown in Table 1, where diode power dissipation and temperature rise exceed those of the MOSFET for the same current.

\section{Evaluation USING $100{ }^{\circ} \mathrm{C}$ COOLANT}

After switching tests using $80{ }^{\circ} \mathrm{C}$ coolant, a chiller upgrade to a pressurized coolant loop enabled higher temperature testing. The module was DC tested again at currents up to 400 A with $100{ }^{\circ} \mathrm{C}$ coolant at $1.9 \mathrm{lpm}, 3.8 \mathrm{lpm}$, and $7.6 \mathrm{lpm}$. Thermal data was acquired and the module was moved back to the boost converter test bed for evaluation using $100{ }^{\circ} \mathrm{C}$ coolant. Fig.11 shows the relationship between individual MOSFET die temperatures during the 400 A (total switch current) DC tests for all coolant temperatures at $3.8 \mathrm{lpm}$. The total drain-to-source voltage recorded for both switches (Q1 and Q2) was higher for the $100{ }^{\circ} \mathrm{C}$ coolant tests than for the $80{ }^{\circ} \mathrm{C}$ coolant tests. Therefore, an increase in effective $\mathrm{ON}$ state resistance of both switches occurred. Although not all $\mathrm{SiC}$ MOSFET die follow the exact same ON-state resistance trend with temperature, in general this result can be expected from the plot shown in Fig. 2.

Die temperature rises for each coolant temperature (each data set) are proportional to die power dissipation. This is true within each data set having the same average thermal resistance, but not necessarily true between tests having different coolant temperatures. The afore mentioned effect of increased natural convection from un-encapsulated die surfaces at increased temperatures above ambient results in lower thermal resistances, and therefore lower switch temperatures. For example, Q2 had a total power dissipation of $688 \mathrm{~W}$ and an average die temperature rise of $29^{\circ} \mathrm{C}$ at 400 A DC using $80{ }^{\circ} \mathrm{C}$ coolant at $3.8 \mathrm{lpm}$. Using $100{ }^{\circ} \mathrm{C}$ coolant under the same conditions, Q2 had a total power dissipation of $704 \mathrm{~W}$ and an average die temperature rise of $28^{\circ} \mathrm{C}$.

The 400 A DC $100{ }^{\circ} \mathrm{C}$ coolant data of Fig. 11 shows a rise in the temperature trend of die numbers $4,5,6$, and 7 of both switches (Q1 and Q2 from right to left in Fig. 4). Because all die per switch are connected in parallel, they have the same voltage drop for each data set. Therefore, die having higher temperature rises, conduct a larger portion of the total switch current, and thereby have a lower $\mathrm{ON}$-state resistance relative to the other die of the switch. Based on total switch current (400A), die temperature rise data was used to compare die $\mathrm{ON}$-state resistances between the $80{ }^{\circ} \mathrm{C}$ and $100{ }^{\circ} \mathrm{C}$ coolant tests. For both switches in the $100{ }^{\circ} \mathrm{C}$ coolant tests, calculations show die numbers 1,2 , and 3 having reduced ON-state resistances, and die numbers 4, 5, 6, and 7 having increased ON-state resistances. Die numbers 5, 6, and 7 of switch Q1, were fabricated on a different wafer than all other module die, which may explain the different ON-state resistance trend. The smaller trend deviation of the die of switch Q2 cannot be correlated with wafer numbers, but actually provides a more balanced ON-state resistance condition. This is expected from the ON-state resistance positive temperature coefficient in this temperature range.

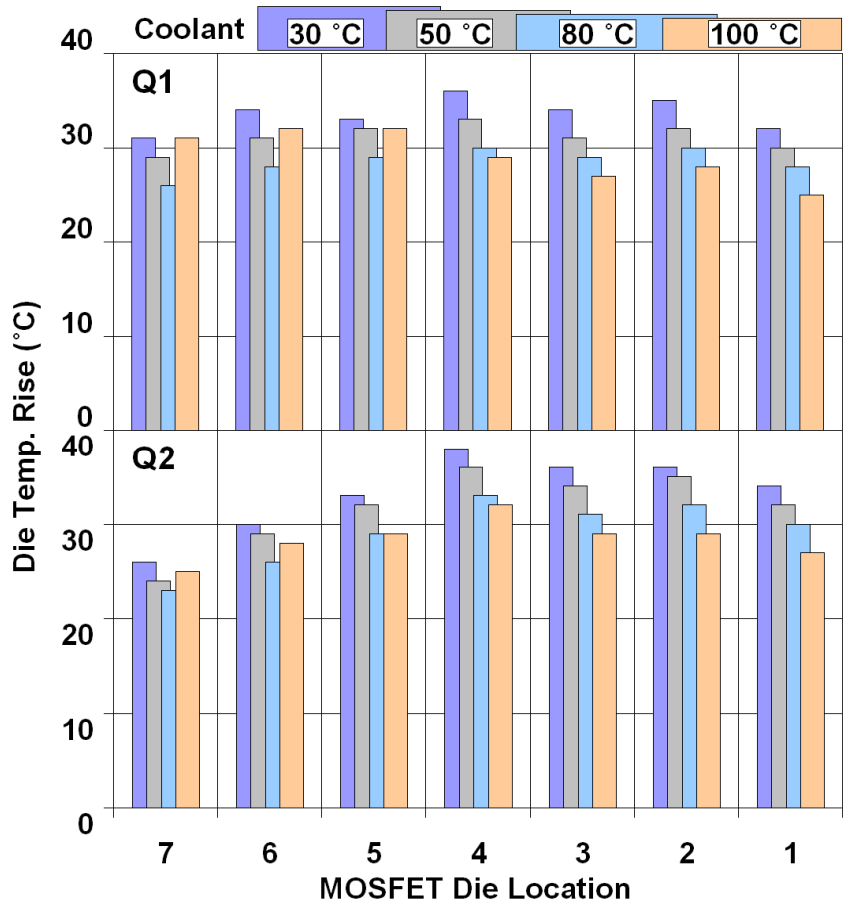

Fig. 11. MOSFET die temperatures for $400 \mathrm{~A} \mathrm{DC}$ (per switch), $30{ }^{\circ} \mathrm{C}, 50{ }^{\circ} \mathrm{C}$, $80{ }^{\circ} \mathrm{C}$, and $100{ }^{\circ} \mathrm{C}$ coolant at $3.8 \mathrm{lpm}$.

Data from the first set of switching tests at $10 \mathrm{kHz}$ and 100 ${ }^{\circ} \mathrm{C}$ coolant was acquired. During the next test set, at $15 \mathrm{kHz}$, one or more lower switch (Q2) MOSFET die failed causing a short circuit resulting in an over-current of several devices. Failure analysis revealed five shorted devices (die numbers 1, 2, 3, 4, and 5 from right to left in Fig. 4) and the three other devices having unstable leakage currents at drain blocking voltages of $500 \mathrm{~V}$.

An exact mode of failure for the power module is difficult to determine based on the experimental data collected. It is not known whether failure occurred during the ON-state, the blocking-state, or during transition between the two. The temperatures of the MOSFET die during switching tests preceding the failure did not indicate in either magnitude or distribution that a failure was imminent. The data suggests appropriate current sharing among the devices in the ONstate, and switching waveforms showed that drain-to-source voltages remained low until transition to the OFF-state. Therefore, module failure is likely to have occurred during 
the OFF-state if the OFF-state leakage current increased significantly through one or more of the over 100,000 device cells on each die. Thermal imaging can be ineffective in determining device leakage on the cell level due to low resolution, and die heat spreading. The threshold voltage $(\mathrm{Vt})$ instability effect, which has been identified as a primary reliability concern, could shift Vt more negatively causing an increase in the leakage current [10],[11]. This effect is exaggerated at elevated device temperatures, and over time could cause device and module failure. A second module has been fabricated with reduced terminal inductance and reduced gate lead inductance and shall be used to verify these results and extend operation to higher temperatures and power levels.

\section{SiC MOSFET MODULE COMPARISONS}

Recent developments of SiC MOSFET multi-chip power modules and those presented herein, demonstrate the pending emergence of this technology into the commercial marketplace. SiC MOSFET-based power modules have also been developed by General Electric (GE), and Powerex, Inc. with current ratings from $100 \mathrm{~A}$ to $550 \mathrm{~A}$ [12]-[14]. GE has used internally fabricated $1200 \mathrm{~V}, 15 \mathrm{~A}$ SiC MOSFET devices having a die size of $0.1 \mathrm{~cm}^{2}$, and $1200 \mathrm{~V}, 10 \mathrm{~A}$ antiparallel JBS diodes to form 150 A single switch modules. Two such modules were used for the high- and low-side switch-diode pairs to form a half-bridge. Pulse testing was used to characterize switching losses of the low-side switch at junction temperatures up to $175{ }^{\circ} \mathrm{C}$. High frequency $(200$ $\mathrm{kHz}$ ) operation of a buck converter at a $2 \mathrm{~kW}$ load power was also demonstrated [12]. In [13], five $0.22 \mathrm{~cm}^{2}, 1200 \mathrm{~V}, 20 \mathrm{~A}$ SiC MOSFET and three $0.36 \mathrm{~cm}^{2}, 1200 \mathrm{~V}$, JBS diodes per switch, manufactured by Cree, Inc., were used by Powerex, Inc., to fabricate a dual 100 A half-bridge module evaluated in high temperature pulse testing by the Air Force Research Laboratory. In [14], a $1200 \mathrm{~V}, 550 \mathrm{~A}$ dual power module was fabricated by Powerex, Inc., and evaluated by the Army Research Laboratory (ARL). The module, having a $157 \mathrm{~mm}$ by $122 \mathrm{~mm}$ integrated heat sink was populated with eleven $0.56 \mathrm{~cm}^{2} \mathrm{SiC}$ MOSFET die per switch. The $550 \mathrm{~A}$ dual module was complementary switched in a full-bridge converter at $5 \mathrm{kHz}, 800 \mathrm{~A}$ peak (400 A rms) per switch, across a $600 \mathrm{~V}$ DC bus.

The work presented in this paper summarizes ARL's development and evaluation of a 400 A dual SiC MOSFET module. The ARL 400 A module demonstrated continuous DC operation at its rated current of over $2.5 \mathrm{x}$ those reported for pulse tests in [12],[13]. Furthermore, the ARL module was evaluated over a range of continuous operating conditions up to $30 \mathrm{kHz}$ and $225 \mathrm{~A} \mathrm{rms}$ in a switching converter. This result shows high current switching at frequencies exceeding those reported in [14]. Finally, the ARL 400 A module exceeded the DC current density (current per unit area) by more than a factor of two, compared to the dual modules in [13],[14].

\section{SUMMARY}

In conclusion, a $1200 \mathrm{~V}, 400 \mathrm{~A}$ dual all SiC MOSFET module was fabricated in a package having the form factor of a 300 A to 400 A rated commercially available dual IGBT module. Device current sharing and power losses under DC and power switching conditions were evaluated. Die were not encapsulated, allowing IR thermal imaging, but limiting peak switch voltage during testing. The module was evaluated in DC tests at up to $400 \mathrm{~A}$ at coolant temperatures up to $80{ }^{\circ} \mathrm{C}$ with maximum MOSFET die temperatures of approximately $110{ }^{\circ} \mathrm{C}$. Lower MOSFET ON-state resistances were observed with increasing die temperatures consistent with the negative temperature coefficient over this range. Switching tests in a DC-DC boost converter at Q2 rms currents up to 225 A (limited by peak drain voltage) and switching frequencies up to $30 \mathrm{kHz}$ were run at coolant temperatures up to $80{ }^{\circ} \mathrm{C}$. Power losses calculated from the experimental data for both the MOSFETs and diodes were compared to those of a silicon high speed 400 A dual IGBT module simulated over the same electrical operating conditions. Results showed the silicon-carbide MOSFET module to have dramatically lower losses than the silicon IGBT module. DC tests up to $400 \mathrm{~A}$ per switch were run using $100{ }^{\circ} \mathrm{C}$ coolant with approximate die temperatures of $130{ }^{\circ} \mathrm{C}$, and the positive temperature coefficient of MOSFET $\mathrm{ON}$-state resistance was observed. These application based experiments, and their corresponding results, expand on those reported in [12]-[14] to demonstrate that the development of multi-chip all $\mathrm{SiC}$ switch modules is feasible for high power converter applications using high temperature coolant.

\section{ACKNOWLEDGMENT}

The authors gratefully acknowledge the contributions of the following engineers, scientists, and technicians, of the Adelphi Laboratory Center: Mrs. Gail Koebke and Mrs. Lauren Boteler for module packaging; Mr. Ronald Duane and Mr. Donald Porschet for the fabrication of heat sink materials; Mr. Gregory Ovrebo for fluid simulations; Mr. Nicholas Jankowski for module case material fabrication; Mr. Robert Wood for module evaluation support and guidance; and Dr. C. Wesley Tipton for technical leadership.

\section{REFERENCES}

[1] Sei-Hyung Ryu, S. Krishnaswami, B. Hull, B. Heath, M. Das, J. Richmond, H. Fatima, J. Zhang, A. Agarwal, J. Palmour, A. Lelis, B. Geil, D. Katsis, C. Scozzie, and J Scofield, "High Speed Switching Devices in 4H-SiC - Performance and Reliability," in Proc. 2005 IEEE International Semiconductor Device Research Symposium, pp. 162163.

[2] J. A. Cooper Jr., and A. Agarwal, "SiC Power-Switching Devices - The Second Electronics Revolution?," in Proc. of the IEEE, vol. 90, pp. 956-968, June 2002.

[3] B. A. Hull, M. K. Das, Sei-Hyung Ryu, S. K. Haney, C. Jonas, C. Capel, L. Hall, J. Richmond, R. Callanan, F. Husna, A. Agarwal, A. Lelis, B. Geil, C. Scozzie, "Status of 1200V 4H-SiC Power DMOSFETs," in Proc. 2007 IEEE International Semiconductor Device Research Symposium, pp. 1-2.

[4] T. E. Salem, D. P. Urciuoli, R. Green, and G. K. Ovrebo, "HighTemperature High-Power Operation of a 100 A SiC DMOSFET 
Module," in Proc. 2009 IEEE Applied Power Electronics Conf., pp. 653-657.

[5] D. P. Urciuoli, R. A. Wood, T. E. Salem, and G. K. Ovrebo, "Design and Development of a 400 A, All Silicon-Carbide MOSFET Power Module," presented at the NDIA MI 2008 Ground-Automotive Power \& Energy Workshop, Warren, MI, 2008.

[6] L. Boteler, D. Urciuoli, G. Ovrebo, D. Ibitayo, and R. Green, "Thermal Performance of a Dual $1.2 \mathrm{kV}, 400$ A Silicon-Carbide MOSFET Power Module," in Proc. 2010 IEEE SEMI-THERM Symposium, pp. 170-175.

[7] D. Ibitayo, D. Urciuoli, G. Koebke, and R. Green, "Fabrication and Analysis of a Dual $1.2 \mathrm{kV}, 400$ A Silicon-Carbide MOSFET Power Module," in Proc. 2010 GOMACTech Conf., pp. 99-102.

[8] T. E. Salem, D. Ibitayo, and B. R. Geil, "Calibration of an Infrared Camera for Thermal Characterization of High Voltage Power Electronic Components," in Proc. 2005 IEEE Instrumentation and Measurement Technology Conf., pp. 829-833.

[9] R. A. Wood, D. P. Urciuoli, T. E. Salem, and R. Green, "Reverse Conduction of a 100 A SiC DMOSFET Module in High-Power Applications," in Proc. 2010 IEEE Applied Power Electronics Conf., pp. $1568-1571$

[10] S. Ryu, B. Hull, S. Dhar, L. Cheng, Q. Zhang, J. Richmond, M. Das, A. Agarwal, J. Palmour, A. Lelis, B. Geil, and C. Scozzie, "Performance, Reliability, and Robustness of $4 \mathrm{H}-\mathrm{SiC}$ Power DMOSFETs," Materials Science Forum, vols. 645-648, pp. 969-974, Apr. 2010.

[11] A. J. Lelis, R. Green, D. Habersat, and N. Goldsman, "Effect of ONstate Stress on SiC DMOSFET Subthreshold I-V Characteristics," Materials Science Forum, vols. 645-648, pp. 983-986, Apr. 2010.

[12] L. D. Stevanovic, K. S. Matocha, P. A. Losee, J. S. Glaser, J. J. Nasadoski, S. D. Arthur, "Recent Advances in Silicon Carbide MOSFET Power Devices," in Proc. 2010 IEEE Applied Power Electronics Conf., pp. 401-407.

[13] J. Scofield, N. Merrett, J. Richmond, A. Agarwal, and S. Leslie, "Electrical and Thermal Performance of $1200 \mathrm{~V}, 100 \mathrm{~A}, 200^{\circ} \mathrm{C} 4 \mathrm{H}-\mathrm{SiC}$ MOSFET based Power Switch Modules," presented at the International Conf. on Silicon Carbide and Related Materials, Nuremberg, Germany, 2009.

[14] R. A. Wood and T. E. Salem, "Characteristics of a 1200 V, 550 A SiC DMOSFET Dual Module," in Proc. 2010 PCIM Europe International Exhibition and Conf. for Power Electronics, pp. 293-298. 